\title{
Potential valorisation of shredder fines: Towards integrated processes formaterial upgrading and resource recovery
}

Tharaka Gunaratne, J oakim Krook, Hans Andersson and Mats Eklund

The self-archived postprint version of this journal article is available at Linköping University Institutional Repository (DiVA):

http:/ / urn.kb.se/ resolve?urn=urn:nbn:se:liu:diva-167036

N.B.: When citing this work, cite the original publication.

Gunaratne, T., Krook, J ., Andersson, H., Eklund, M., (2020), Potential valorisation of shredder fines: Towards integrated processes formaterial upgrading and resource recovery, Resources, Conservation and Recycling, 154, . https:// doi.org/ 10.1016/j.resconrec.2019.104590

Original publication available at:

https:// doi.org/ 10.1016/j.resconrec.2019.104590

Copyright: Elsevier

http:// www.elsevier.com/

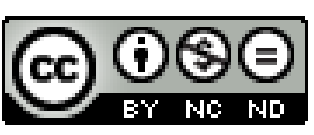




\title{
Potential valorisation of shredder fines
}

\author{
Towards integrated processes for material upgrading and resource recovery
}

Tharaka Gunaratne (corresponding author) environmental technology and management, linköping university, Joakim Krook environmental technology and management, linköping university, Mats Eklund environmental technology and management, linköping university, Hans Andersson business administration, linköping university

Linköping University, Environmental Technology and Management, 58183 Linköping, Sweden

tharaka.gunaratne@liu.se, joakim.krook@liu.se,mats.eklund@liu.se, hans.andersson@liu.se

\section{Abstract}

The lack of process development based on a comprehensive understanding of the material characteristics and the marketability of recoverables is the primary reason why the valorisation of shredder fines has not been realised in practice. In response, a systematic approach was undertaken consisting of 1) strategic sampling and material characterisation, 2) establishing gate and regulatory requirements of potential valorisation applications, and 3) initial feasibility assessment of the selected applications, to guide future research.

The material was sampled over ten weeks in order to obtain both average values and variations of the physical and chemical composition. Thus weekly, primary fractions and sieved fractions ZA (7.10-5.00 mm), ZB (5.00$3.35 \mathrm{~mm}), \mathrm{ZC}(3.35-2.00 \mathrm{~mm}), \mathrm{ZD}(2.00-0.25 \mathrm{~mm})$, and ZE $(0.25-0.063 \mathrm{~mm})$ were prepared, and analysed, and benchmarked against the requirements pertaining to five potential applications. The mercury and aluminium concentrations are the biggest challenge in copper smelting and only ZA and ZB show significant potential. Energy recovery is limited to ZA, ZB, and ZC, provided the chlorine and metals concentrations are decreased. Regarding the recovery as bulk-material in construction, the reduction of the metal content would likely be a pre-requisite.

The utilisation of fines in the individual applications would either leave a significant amount of fines unvalorised or overlook the recovery of valuable resources. The upgrading of the material to suit the different applications would also require addressing multiple material constraints simultaneously. Therefore, realising the full resource potential of shredder fines would require the integration of different upgrading and recovery processes.

Keywords: Shredder fines, Valorisation, Upgrading, Recovery, Characterisation, User requirements

\section{Introduction}

Shredder fines (also known as fines) is the fine granular fraction of shredder residues, which is the production residue generated by the shredding industry. In this industry, waste streams such as end-of-life vehicles (ELVs) after depollution and dismantling, white goods, and industrial metallic scrap are shredded where ferrous and non-ferrous (aluminium and copper) metals are initially recovered. The remainder is the shredder residue, which consist of a variety of different materials such as metals, plastics, textile and fibre, rubber, foam, glass, wood and gravel (Santini et al., 2012; Vermeulen et al., 2011). The fine fraction of the shredder residue is called "shredder fines" or just "fines". Shredder fines is typically identified below $20 \mathrm{~mm}$ and could constitute 5\%-17.5\% of the total output of a shredding plant - calculated from (Cossu et al., 2014; Vermeulen et al., 2011), and has no residual value. Despite several studies having investigated the management of shredder residue (Cossu et al., 2014; Cossu and Lai, 2015; Vermeulen et al., 2011), research that specifically address shredder fines is sparse. Certain commercial post-shredder treatment technologies such as VWSiCon, Galloo, and R-Plus, which are specifically developed for the treatment of ELVs, are capable of recovering between $90 \%-100 \%$ of the automobile shredder residue (GHK and Bio Intelligence Service, 2006), meaning that fines is partly or fully recovered. Nevertheless, shredder fines is largely disposed of in many parts of world.

In Sweden, fines is mostly used as landfill cover material, whereas on certain occasions it is also landfilled. The main reasons why fines is used as landfill cover material are the low costs involved and meeting the 
targets of the ELV directive of the European Union (EU) for 95\% recovery and 85\% recycling ${ }^{1}$ of the total weight of ELVs (European Commission, 2000). This practice has evolved since 2010, when landfill covering was recognised as waste recovery, as part of backfilling (European Commission Eurostat, 2011). During the last decades, landfilling has gradually been phased out as a waste management option in Sweden. Due to this closure of landfills, a large demand for alternative cover materials such as shredder fines has existed previously. However, at present, given that most of these landfills already have been covered, the option of using shredder fines as a cover material is rapidly disappearing. Hence, to reduce waste disposal costs and fulfil the ELV directive targets, the shredding industry is motivated to develop alternative applications for the valorisation (upgrading and recovery) of shredder fines. However, the heterogeneity of the material and the small particle size make the development of applications challenging from both a technical and economic point of view (Fischer, 2006; Vermeulen et al., 2011).

Although the development of processes for recovery constitutes one of the main topics in previous research on shredder fines, most of these studies have only considered one specific type of recovery at a time. This means that the full resource potential (i.e. exploitation of both the recovery of valuable resources and minimising the disposable quantity via utilisation as bulk-material in certain applications) shredder fines has often been overlooked. For instance, there are several studies focusing only on the recovery of metals such as copper and zinc from fines (Lewis et al., 2011; Reuter et al., 1999; Singh et al., 2017, 2016a; Singh and Lee, 2016), while others instead target the bulk utilisation of fines as a substitute material in applications such as construction applications and plastics moulding (Cain et al., 2000; Péra et al., 2004; Robson and Goodhead, 2003; Rossetti et al., 2006). In regard to the former, once metals are recovered there will still be a large quantity of fines left un-valorised. As concerns the latter, a substantially larger quantity of fines could be valorised, nevertheless the opportunity to recover valuable resources such as metals and energy carriers is lost. Furthermore, most of these studies involve early-stage laboratory research in which the technical process parameters are typically in focus. This is perhaps one main reason why the marketability of the process outputs has rarely been considered. However, such market requirements could, in fact, constitute essential process design parameters to facilitate different types of recovery, because the marketplace determines the desirable properties of the incoming materials and also indicates possible material constraints that need to be addressed. A comprehensive understanding of such marketable resource potential and material constraints of shredder fines is currently absent. This could be one of the underlying reasons for the limited scope in previous research.

The aim of this study is to provide knowledge that could guide future research on integrated process development for the valorisation (upgrading ${ }^{2}$ and recovery) of fines to harness the full recovery potential of the material. There, it is also implicit that such process development should emanate based on a comprehensive understanding of the material characteristics and identification of the user requirements. In doing so, the following research questions are answered; a) how could the identification of the resource potential of shredder fines be facilitated through systematic sampling and characterisation of the material, b) what are the market requirements for accepting fines in different recovery applications, and what are the material constraints that need to be addressed in order to meet those requirements, c) how to facilitate the exploitation of the full resource potential in shredder fines? In essence, this is done by benchmarking the physical and chemical characteristics of shredder fines against the gate and regulatory requirements of a selected number of conventional recovery applications. There, the material constraints that need to be addressed in order to facilitate recovery in each application are specified. Based on these results, key research challenges for recovering marketable fines-derived resources as well as the utilisation of fines as a whole are discussed. This is an initial feasibility assessment that does not deal with actual process development and all the aspects that need to be considered in such work. Rather, the focus is to provide guidance on the need for integrated process development for the valorisation of fines. Here, the marketability is limited to the gate requirements of the selected downstream industries that utilise waste-derived (secondary) materials, and the respective regulatory requirements.

\footnotetext{
1 "Recovery" is any operation by means of which a waste is used or being prepared to serve a particular function by replacing other materials, and "recycling" means any recovery operation by which waste materials are reprocessed into products, materials, or substances whether for the original or other purposes. (European Commission, 2008).

2 The processing of the material to overcome the specific material constraints pertaining to a particular recovery application.
} 


\section{Materials and methods}

The applied analytical approach undertaken in this study can be divided into three main steps. First, shredder fines from a major shredding plant in Sweden was strategically sampled and characterised with respect to an array of chemical and physical properties. This characterisation was done to identify potentially recoverable resources in fines, as well as develop knowledge about possible material constraints for such recovery. In the second step, five commercially available recovery applications in Sweden were selected as potential valorisation options for shredder fines. These applications represent different areas of valorisation so that the recovery of specific types of materials and energy resources, as well as the utilisation of fines as a whole, could be encompassed. For each application, the gate requirements of the corresponding recovery facility and the regulatory conditions that govern such recovery were then established. Finally, in the third step, the material characteristics of fines were benchmarked against the gate and regulatory requirements of the different recovery applications. This initial feasibility assessment was done to provide specifications of requirements for upgrading processes, in terms of the different material constraints that need to be addressed in order to facilitate the different types of recoveries. Based on this assessment, guidelines for future research on both upgrading processes and recovery strategies are developed, emphasizing the need for integrated approaches that could address the multiple material constraints of shredder fines and enable a more effective valorisation of the resource potential of this material.

\subsection{Sampling and characterisation of shredder fines}

The studied material originates from a major shredding plant in Sweden (Figure 1), in which approximately 500,000 tonnes of material (i.e. a mix of ELVs, municipal white goods, and industrial metallic scrap in approximately equal shares) are annually processed. The post-shredder recovery process starts by separating the shredded material into a light and a heavy fraction. Shredder fines is produced after recovering ferrous metals from the light fraction. At this plant, shredder fines is the sieved residue (i.e. less than about $10 \mathrm{~mm}$ ) of the light fraction followed by initial metals recovery. In total, about $10-15 \%$ of the input to the shredder ends up as shredder fines.

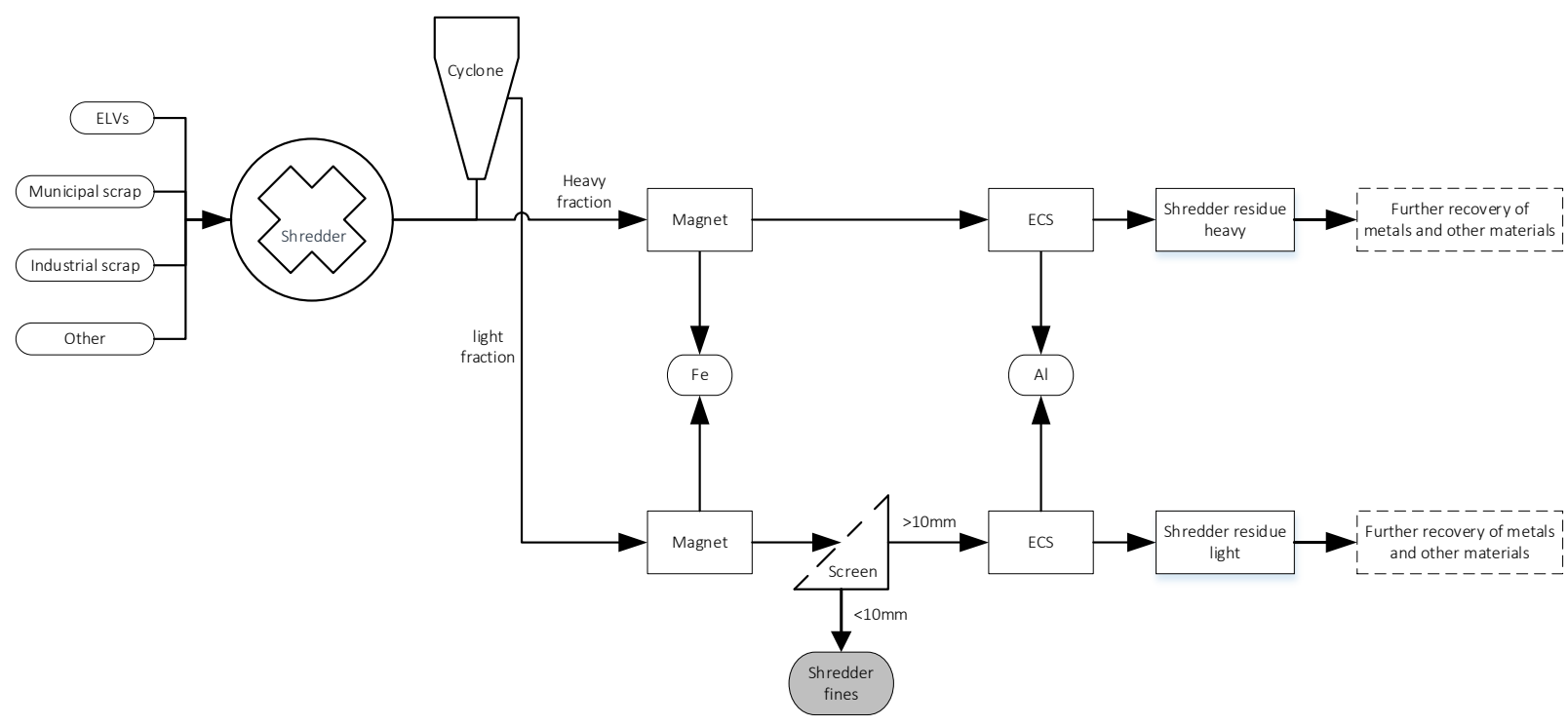

Figure 1: Shredding process of the involved shredding plant.

In previous research, the characterisation of shredder fines for the estimation of resource or contamination potential has been mostly performed indirectly as part of shredder residues (Ahmed et al., 2014; Fiore et al., 2012; Gonzalez-Fernandez et al., 2008; Morselli et al., 2010). Direct characterisation of the material has been performed only to facilitate the development of a certain recovery process (Bareel et al., 2006; Konetschnik and Schneeberger, 2009; Péra et al., 2004; Simona et al., 2017). Nevertheless, in these studies, the characterisation has often been limited to one or two randomly collected samples. Given that the composition of this material could vary over time depending on variations in the feed material, such an approach to sampling implies uncertainties in the obtained values. When it comes to the development of different 
valorisation options, using such limited knowledge about the material characteristics means that compliance with regulatory conditions and end user requirements could be misinterpreted. In-depth knowledge about the variation in composition is also necessary to capture crucial design parameters and develop the technical and economic feasibility of recovery processes (Allegrini et al., 2014; European Commission, 2004). Therefore, in this study, the main strategy of the sampling procedure was to capture the variation (over time) in the composition of the material, in addition to the average values.

Hence, a sampling plan (Figure 2) was prepared and executed in consultation with the Swedish standards for waste sampling and characterisation (Swedish Standards Institute, 2006). The sampling was performed over a nine-week period, where a sample of shredder fines (approximately 5 litres) was collected directly from the source, twice a week (every Monday and Thursday), and every other week. This approach was selected to cover some of the monthly variation, and the reason for collecting samples during these two days was to make sure that the analysed material originates from different batches of feed material. The two collected samples from each week were initially dried for eight hours at $105^{\circ} \mathrm{C}$ and then stored under refrigerated conditions $\left(4-8{ }^{\circ} \mathrm{C}\right)$. Subsequently, the two samples were thoroughly mixed to form a weekly primary sample of about 10 litres. Each weekly primary sample was then divided into four quarters, where three quarters (about 7.5 lit) were put together to create a fraction that was used for the analysis of total elemental concentrations (TC-fraction), while the remaining quarter (about 2.5 lit) was used for heavy metal leaching tests (LC-fraction). Both these fractions were further processed prior to sending them for chemical analysis to the laboratory, a laboratory accredited by the Swedish Standard Institute. Regarding weekly TC-fractions, one-third was isolated to represent the primary sample (e.g. SW1Y). This sub-sample is called the primary fraction in this paper. The remainder was sieved into five different size fractions (e.g. SW1ZA, SW1ZB). These sub-samples are called sieved fractions in this paper. The sieved fractions were prepared and characterised in order to identify any major differences between them and also based on the premise that different particle sizes might suit different recovery and recycling applications due to varying chemical and physical properties. Regarding weekly LC-fractions, the samples from week 3 and week 7 were prepared in the same manner as described for the TC-fractions. That is, both primary fractions and sieved fractions were prepared and sent for laboratory analyses. However, LC-fractions from weeks 1, 5, and 9 were not processed to isolate sieved fractions, and therefore, only primary fractions were sent for the laboratory analyses. 

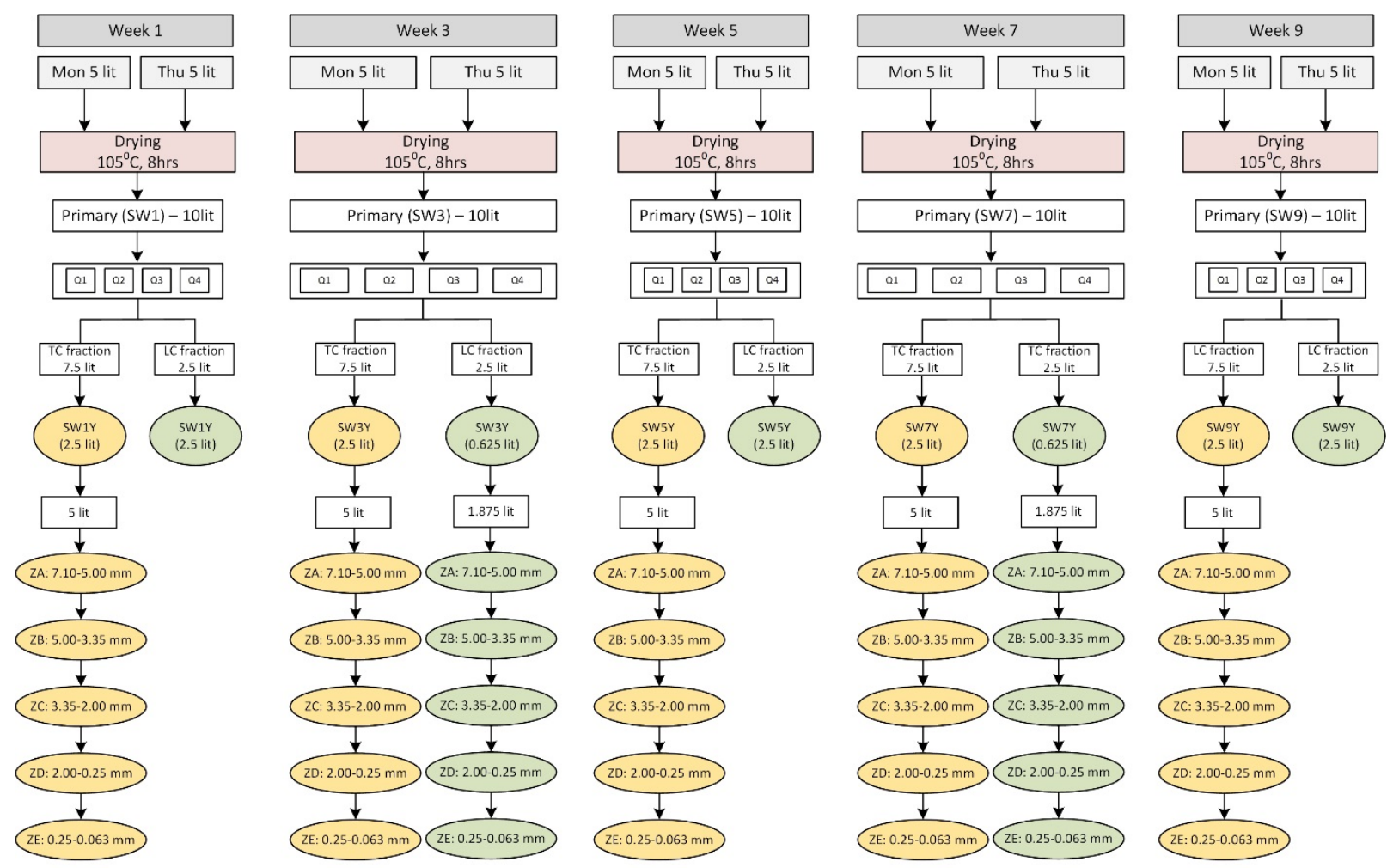

$\bigcirc$ Sample preparation for total concentration tests

Sample preparation for leaching concentration tests

Figure 2: Sampling plan and preparation of sub-samples for the laboratory analyses.

The two main objectives of the characterisation of the chemical and physical composition of the material were to assess the resource potential of the material and develop a broad knowledge on possible material constraints for resource recovery. Thus, the characterisation involved the analysis of total concentrations for 25 metals and fuel properties (i.e. heating value, ash content, moisture content, chlorine concentration, and sulphur concentration), and leaching concentrations (L/S 10, Swedish standard) for 12 regulated metals and anions. The total metals concentration was prioritised because it strongly influences the compliance with the regulatory requirements as well as the gate requirements of all commercial applications for waste recovery in Sweden. As far as the use of waste in ground construction applications (non-structural constructions on the ground - e.g. road base layer, pavements, parking lots, and noise barriers, etc.) and landfill covering is concerned, the Swedish Environmental Protection Agency (EPA) also considers the leaching concentration in the assessment of the environmental risk. The leaching concentration tests were performed only for a selected number of sub-samples due to budgetary constraints.

The total concentration analyses were performed on primary fractions ( $\mathrm{Y}$ sub-samples) and sieved fractions ( $\mathrm{Z}$ sub-samples) from all the five weeks. In order to perform the leaching concentration analyses, the previously stored portions of fines (SWIX, etc.) were further processed into primary fractions and sieved fractions. The leaching concentration analyses were performed on the primary fractions ( $Y$ sub-samples) from all weeks and sieved fractions ( $\mathrm{Z}$ sub-samples) from week 3 and week 7 . The analysis of size fractions was limited to two weeks due to budgetary constraints, nevertheless, week 3 and week 7 were selected with the idea of representing some sort of symmetry within the five occasions of the nine weeks period.

\subsection{Selection of recovery applications and establishment of gate and regulatory requirements}

Five potential recovery applications for the valorisation of shredder fines were chosen based on the initial material characterisation and current practices for managing industrial production residues in Sweden (Figure 3). Despite the presence of a number of emerging, non-conventional applications reported in the literature, this study was limited to already existing conventional practices because it is only for such applications that 
some gate and regulatory requirements could be obtained. However, the studied recovery options were deliberately selected to represent different types of valorisation, ranging from applications that target specific materials and energy carriers to those that rather focus on utilising as much material of fines as possible to avoid disposal. Smelting for copper recovery was selected here because it is currently practiced for the metalsrich larger fractions of shredder residues as well as for electrical and electronic waste, and certain sieved fractions of shredder fines contained considerable amounts of copper. The reasons for including different energy recovery applications were similar. Fuel recovery in cement kilns and municipal solid waste incinerators is today common for plastics and foam-rich larger fractions of shredder residues and many other types of industrial residues, and fines was found to contain a substantial organic content. The recovery of fines as bulk-material applications was primarily selected as an option due to its potential in utilising the material as a whole and in large quantities, thereby significantly limiting the need for disposal or alternative treatment. In Sweden, shredder fines is currently being used for landfill covering. However, similar heterogenic residues (e.g. MSWI bottom ash) are widely used in ground construction applications in other European countries (Dou et al., 2017) and occasionally also in Sweden (Miljösamverkan Västerbotten, 2014).

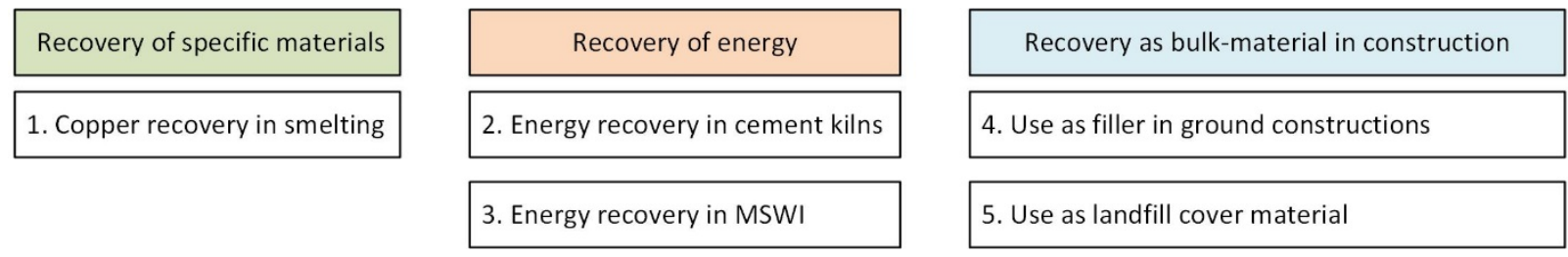

Figure 3: Selected potential applications for shredder fines valorisation. The particular applications are placed under the different types of recovery.

For each of the selected resource recovery applications, the corresponding gate and regulatory requirements were established, primarily, through semi-structured interviews with representatives from the different industries. Thus, eight persons representing seven companies that are operational within the five chosen applications were interviewed (Table 1). Regulatory documents from the Swedish EPA concerning waste management were also reviewed in order to specify guiding values regarding the allowable heavy metal contents in wastes aimed for the different construction applications.

\subsection{Initial feasibility assessment of the selected applications to guide future research on integrated upgrading and recovery of shredder fines}

The previously established material characteristics of shredder fines were benchmarked against the gate and regulatory requirements of the selected recovery applications. The average composition of the different chemical and physical properties of shredder fines were primarily used when assessing the fulfilment of these gate and regulatory requirements. However, the implications of significant variations in the material properties were also taken into account. This initial feasibility assessment was conducted in relation to two parts: (i) identification of the occurrence of recoverable materials and energy resources in the different fractions of shredder fines, and (ii) identification of the material constraints with respect to the different fractions of shredder fines that need to be addressed to fulfil the corresponding gate and regulatory requirements.

The results from the initial feasibility assessment were finally synthesized in order to provide guidance for future research on both upgrading processes and recovery strategies for shredder fines. Here, the benchmarking of material characteristics and gate and regulatory requirements for resource recovery served as a foundation for discussing the need for integrated upgrading processes that could address several of the identified material constraints simultaneously. When it comes to recovery strategies, the emphasis was on assessing to what extent the different applications could contribute to the full valorisation of shredder fines, where as much material as possible is utilised, while recovering particularly valuable resources. The total share of this residue as well as its content of specific materials and energy carriers that could potentially be recovered by the different applications were therefore estimated based on the established material characteristics and the need for upgrading of the different size fractions of shredder fines. 


\begin{tabular}{|c|c|c|c|c|c|}
\hline \multirow{2}{*}{ Application } & \multirow{2}{*}{ Gate requirements } & \multirow{2}{*}{ Regulatory requirements } & \multicolumn{3}{|c|}{ Source of information } \\
\hline & & & Interviewee & Responsibility & Company/operations \\
\hline \multirow{2}{*}{$\begin{array}{l}\text { 1. Metals recovery in } \\
\text { smelting }\end{array}$} & \multirow{2}{*}{$\begin{array}{ll}\text { - } & \text { Recoverable metals } \\
\text { - } & \text { Critical metals } \\
\text { - Impurities } \\
\text { - }\end{array}$} & \multirow{2}{*}{ - Not relevant } & - Interviewee 1 & $\begin{array}{ll}- & \text { Purchasing manager } 1 \text { - } \\
& \text { Secondary raw materials } \\
\end{array}$ & \multirow{2}{*}{ - Smelting } \\
\hline & & & - Interviewee 2 & $\begin{array}{ll}\text { - } & \text { Purchasing manager } 2 \text { - } \\
& \text { Secondary raw materials }\end{array}$ & \\
\hline \multirow{2}{*}{$\begin{array}{l}\text { 2. Energy recovery in } \\
\text { cement kilns }\end{array}$} & \multirow{2}{*}{$\begin{array}{l}\text { - Fuel properties } \\
\text { - Impurities }\end{array}$} & \multirow[t]{2}{*}{ - Total concentrations } & - Interviewee 3 & $\begin{array}{l}\text { - Sales manager -Secondary } \\
\text { raw materials }\end{array}$ & - Shredding \\
\hline & & & - Interviewee 4 & - Alternative fuels manager & - Cement manufacturing \\
\hline \multirow{2}{*}{$\begin{array}{l}\text { 3. Energy recovery in } \\
\text { municipal waste } \\
\text { incinerators }\end{array}$} & \multirow{2}{*}{$\begin{array}{l}\text { - Fuel properties } \\
\text { - Impurities }\end{array}$} & \multirow{2}{*}{ - Total concentrations } & - Interviewee 3 & $\begin{array}{l}\text { - Sales manager -Secondary } \\
\text { raw materials }\end{array}$ & - Shredding \\
\hline & & & - Interviewee 5 & - Head fuels supply & - Municipal waste incineration \\
\hline $\begin{array}{l}\text { 4. Use as filler in road base } \\
\text { layer }\end{array}$ & $\begin{array}{ll}\text { - } & \text { Mechanical properties } \\
\text { - } & \text { Supply quantity } \\
\end{array}$ & \multirow{2}{*}{$\begin{array}{l}\text { - Total concentrations } \\
\text { - Leaching } \\
\text { concentrations }\end{array}$} & \multirow{2}{*}{$\begin{array}{l}\text { - Interviewee } 6 \\
\text { - Interviewee } 7 \\
\text { - Interviewee } 8\end{array}$} & \multirow{2}{*}{$\begin{array}{l}\text { - } \quad \text { Production manager } \\
\text { - } \quad \text { Environment and quality } \\
\text { - coordinator } \\
\text { - } \text { Construction manager }\end{array}$} & \multirow{2}{*}{$\begin{array}{l}\text { - Construction } 1 \\
\text { - Construction } 2 \\
\text { - Construction supplier }\end{array}$} \\
\hline $\begin{array}{l}\text { 5. Use as landfill cover } \\
\text { material }\end{array}$ & $\begin{array}{ll}\text { - } & \text { Chemical properties } \\
& \text { regarding pollutants }\end{array}$ & & & & \\
\hline
\end{tabular}

Table 1: Selected applications and the corresponding gate and regulatory requirements 


\section{$1 \quad 3.1$ Distribution of shredder fines within sieved fractions}

2 The total quantity of shredder fines produced within the nine weeks of sampling varies between 400 and 3600 tonnes per week, and the distribution among the different particle sizes of fines is more or less 4 consistent throughout the whole period (Figure 4). Even though the potential for recovery is different for 5 the sieved fractions due to varying compositions and particle sizes, the sieved fraction ZD $(2.00-0.25 \mathrm{~mm})$ is of 6 particular interest as it accounts for more than half of the total weekly flow (i.e. between 53 and $59 \%$ weight $7 \%$ of the total amount of generated shredder fines). A summary of all the assessed chemical and physical 8 properties of shredder fines is presented in supplementary material.

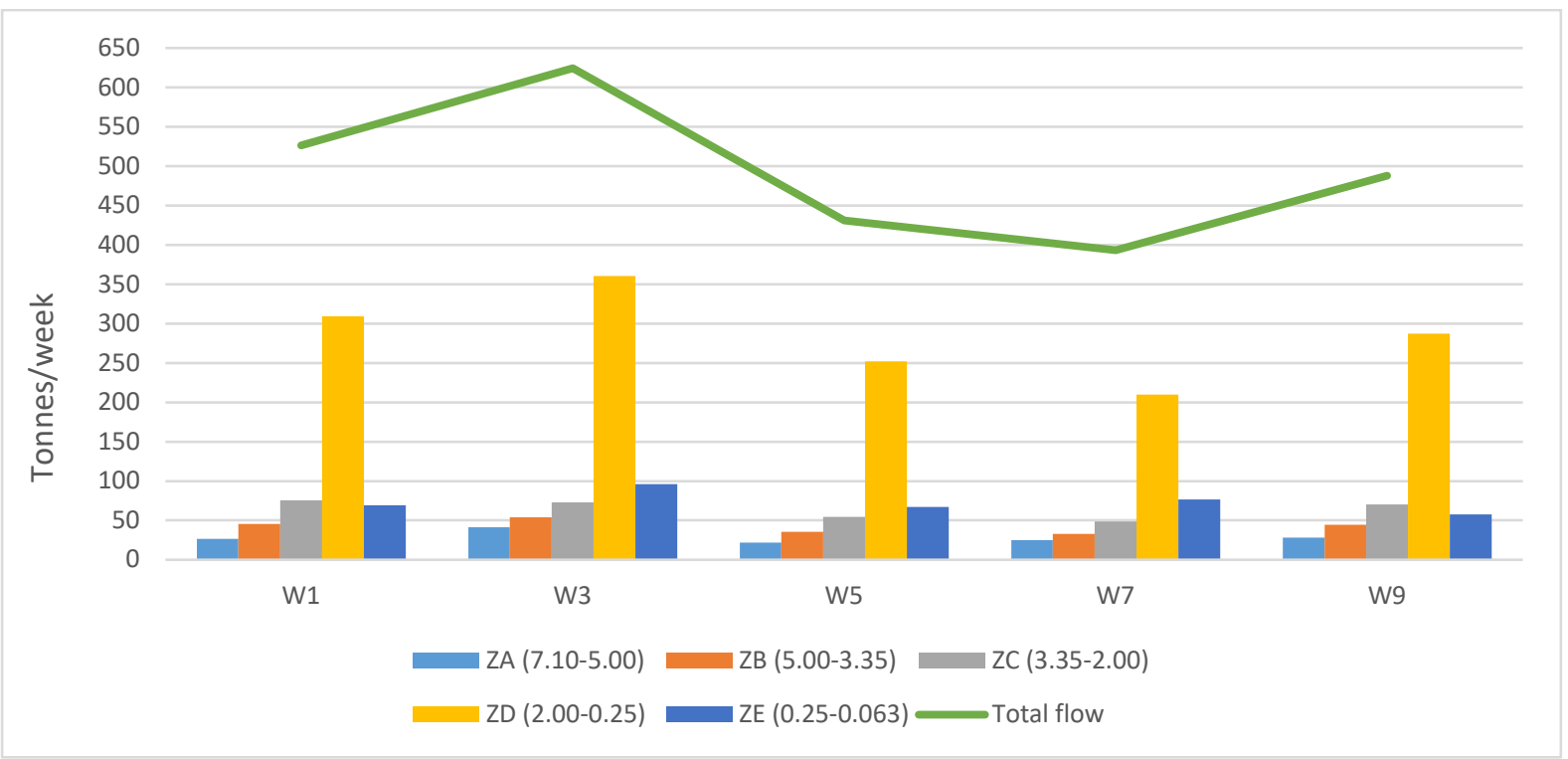

10 Figure 4: Weekly mass flow of shredder fines in total and for different sieved fractions.

\subsection{Copper recovery in smelting}

Mixing of secondary and primary raw materials in metal smelting is common practice in Sweden. Despite low-yield volume additions and higher processing costs compared to primary raw materials, the smelting companies are driven to use secondary raw materials because of the low purchasing cost. Primarily, copper is recovered in the smelters of the company involved in this study. There, the ratio of secondary and primary material in the smelters is 1:5, whereas the total purchasing value of the secondary raw material is negotiated upon the recoverable amount of copper and precious metals such as gold. Therefore, each incoming batch of such material is systematically sampled and analysed prior to agreeing on a purchase price. Currently, these secondary raw materials consist of parts removed from discarded electronic products (called E-scrap) and metal-rich shredder residues (e.g. fractions containing wires and cables). On average, the required copper content is $8 \%$, given that the material in question also contains recoverable amounts of precious metals such as gold (Interviewee $1 \&$ Interviewee 2).

Generally, neither the average copper concentration nor its variation show a recognisable pattern across the different size fractions of shredder fines, other than that the occurrence of this metal in the smallest fraction (ZE) is significantly lower (Figure 5). The highest average copper content in the different sieved fractions of shredder fines is found to be around 3\% ( $\mathrm{ZA})$ and $2 \%(\mathrm{ZB}, \mathrm{ZC}, \mathrm{ZD})$. However, this is significantly below the gate requirement of the smelting plant. The variations show that certain fractions (ZA and ZD) could occasionally provide concentrations up to $6 \%-7 \%$, but nevertheless, there, the significant negative variations (i.e. minimum copper concentrations) imply less reliability. A low copper content is possible to accept given the presence of higher concentrations of recoverable precious metals. However, shredder fines presumably does not contain significant amounts of precious metals, and hence, enriching the fractions to quite high levels of $\mathrm{Cu}$ concentration will be necessary in order to make smelting 
feasible. Accepting shredder fines with a low copper content would however be possible for the smelting company, provided a fee is paid (Interviewee 1 \& Interviewee 2). The size fractions ZA, ZB, ZC, and ZD can therefore be considered the most suitable fractions for further processing, whereas the primary sample and the ZE fraction contain significantly lower copper concentrations.

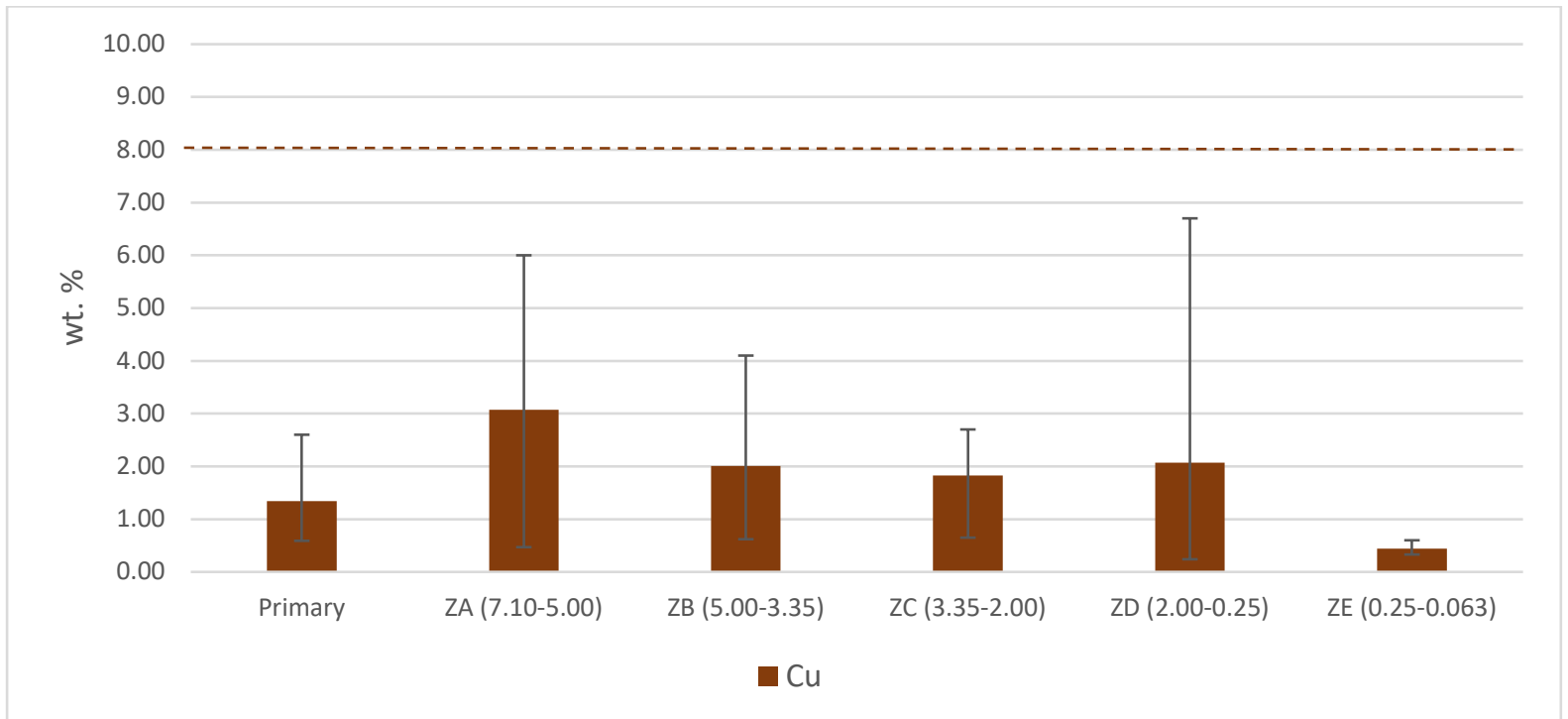

Figure 5: Weekly average concentration of $\mathrm{Cu}$ in the six fractions of shredder fines. The variation over the nine-week sampling period in terms of minimum and maximum values is also shown. The dashed line represents the general gate requirement for the copper concentration.

Even though the gate requirements are quite flexible regarding the recoverable amounts of metals, they are rigid regarding contaminants due to the potential damage certain metals can cause to the smelting process. The most critical metals and their respective maximum allowable limits are beryllium $(\mathrm{Be})$ - undetectable, mercury $(\mathrm{Hg})-2.0 \mathrm{mg} / \mathrm{kg}$, and cadmium (Cd) $-50 \mathrm{mg} / \mathrm{kg}$ (Interviewee 1 \& Interviewee 2). Generally, Beryllium was undetectable in all of the analysed fractions of shredder fines, and the concentrations of the other two metals increase towards the smaller size fractions (Figure 6). In this respect, the fractions ZA and $\mathrm{ZB}$ show the highest potential as feedstock for copper smelting; however, the relatively high average concentrations and positive variations (i.e. maximum concentrations) of mercury in both of these fractions can be of concern. In terms of total recoverable amounts of copper, upgrading of the fraction $\mathrm{ZD}$ is of particular importance as it accounts for more than 50 weight $\%$ of the total amount of generated shredder fines. The two size fractions ZC and ZD show particularly high average concentrations of mercury as well as large positive variations. However, an interesting fact regarding the occurrence of mercury is that the concentrations in all of the fractions (primary and sieved) were well below $2.0 \mathrm{mg} / \mathrm{kg}$ for the first four weekly samples, whereas these concentrations were an order of magnitude higher in the week nine sample. This has not only led to large positive variations, but also to average mercury concentrations exceeding the gate requirements (Figure 6). Average cadmium concentrations are below the gate requirement for all ZA$\mathrm{ZD}$ fractions, while the maximum positive variation has exceeded the limit in the ZC fraction. Therefore, it indicates that using ZA-ZD fractions in copper smelting is feasible in general, despite the occasional infeasibilities due to random increases of the mercury concentrations.

Aluminium and chromium are also two undesirable metals in copper smelting, but not as critical as cadmium and mercury. These metals are undesirable because they end up in slag, which only incurs process costs in terms of waste disposal. In the gate requirements from the smelter, these metals are regarded in terms of their relative concentration to copper. The maximum preferred $\mathrm{Al}: \mathrm{Cu}$ and $\mathrm{Cr}: \mathrm{Cu}$ ratios are 1:1 and 0.1:1 respectively (Interviewee $1 \&$ Interviewee 2). Generally, the $\mathrm{Cr}: \mathrm{Cu}$ ratio increases towards the smaller size fractions, while the $\mathrm{Al}: \mathrm{Cu}$ ratio does not show a particular pattern other than it is significantly higher in the smallest size fraction. The chromium concentration, in general, also shows a greater variation than for aluminium (Figure 6). The size fractions ZC and ZD show considerably more feasibility compared to the others as the occurrences of both aluminium and chromium are quite close to the margins, although high variations in the $\mathrm{ZC}$ fraction is a potential problem. In the fractions $\mathrm{ZA}$ and $\mathrm{ZB}$, the required level is 
more or less attainable with respect to chromium, but the $\mathrm{Al}$ concentration has to be reduced in order to make smelting feasible.
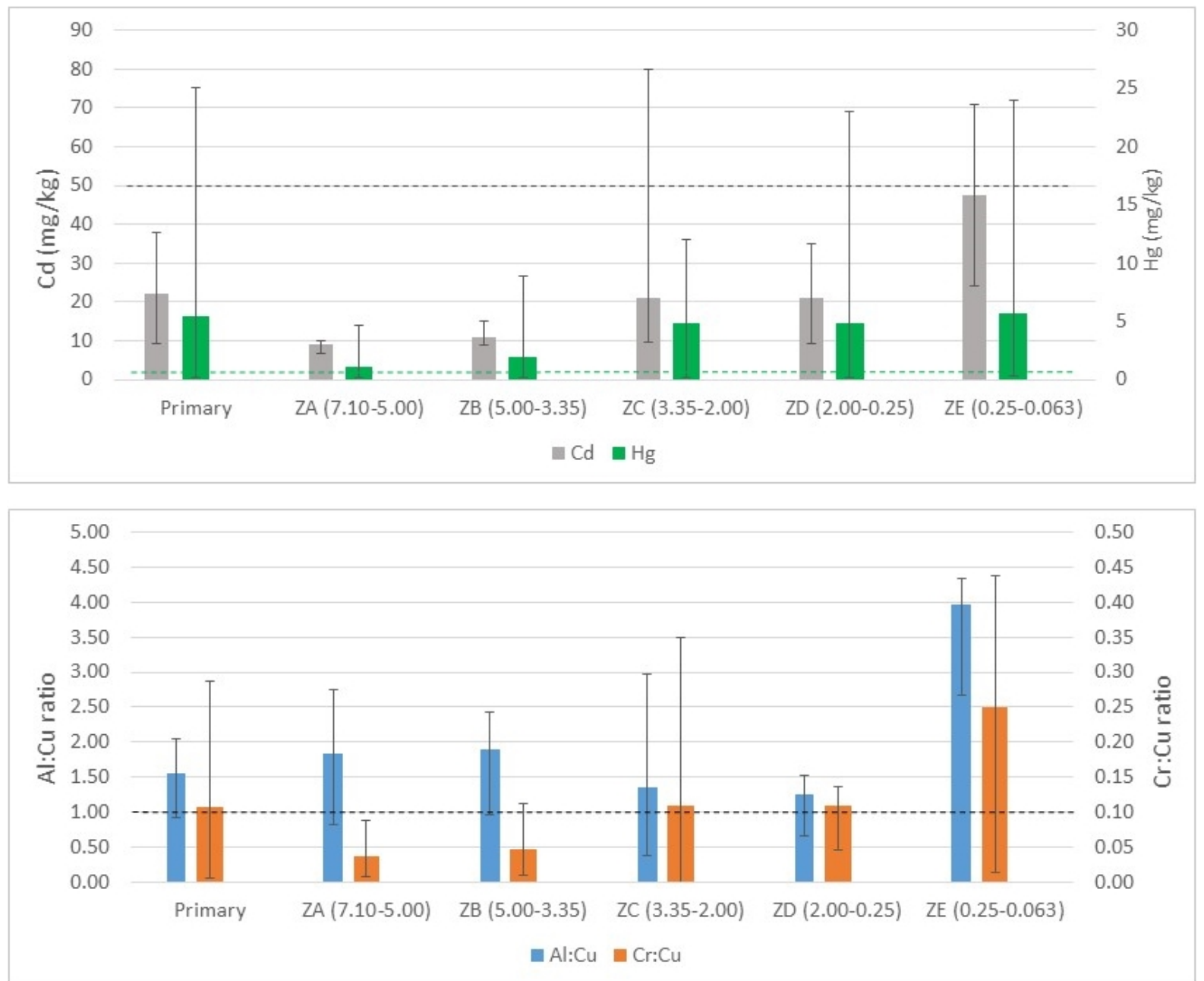

Figure 6: Weekly average concentrations of the critical metals for smelting in the six fractions of shredder fines. The variation in concentrations over the nine-week period in terms of maximum and minimum values is also given. The two most critical metals are cadmium and mercury while the two less critical metals are aluminium and chromium. The dashed line represents the gate requirements (limit values) on the maximum concentrations of the respective metals.

\subsection{Energy recovery in cement kilns and municipal waste incinerators}

Generally, the motivation for using secondary fuels in cement kilns and waste incinerators is caused by the high cost of primary fuels and the availability of secondary fuels within close proximity. The organic content in shredder residues (and thereby in fines) constitutes of wood and a variety of plastics such as polypropylene (PP), polyurethane (PUR), polyvinylchloride (PVC), acrylonitrile butadiene styrene (ABS), poly-methyl-methacrylate (PMMA) and polyethylene terephthalate (PET) (Cossu et al., 2014; Vermeulen et al., 2011). The challenges of using such secondary fuels are the non-uniform distribution of the energy content, reduced thermal efficiency due to improper mixing and scaling, higher emissions of environmentally harmful gases (SOx and NOx), and high corrosion (Chinyama (2011), Interviewee 3, and Interviewee 4). The potential creation of dioxins and dioxin-like substances due to the occurrence of chlorinated substances such as PVC is another significant risk as well (Cossu and Lai, 2015; Zorpas and Inglezakis, 2012).

Gate requirements for the use of shredder fines in both cement kilns and municipal waste incinerators primarily target fuel properties such as heating value, ash content, moisture content, and chlorine concentration (Kaddatz et al. (2013), Interviewee 3, and Interviewee 4). Generally, the heating value 
fines fractions meet the $18 \mathrm{MJ} / \mathrm{kg}$ heating value requirement of the cement kilns. The required heat content for municipal waste incinerators lies between 10 and $14 \mathrm{MJ} / \mathrm{kg}$, and this requirement is more or less fulfilled by the fractions ZA, ZB and ZC. Anything above that range is likely to be charged with an additional gate fee because a uniform distribution of the heat content is necessary to control the combustion process (Interviewee 3 \& Interviewee 5). Nonetheless, this gate requirement applies to continued variations over time. Random high positive variations, such as in ZA, would not be a significant issue. The same applies for negative variations. The ash content in all the fractions is well above the maximum limits for both applications. The relatively high ash content in the coarser fractions could possibly be due to the presence of light weight high-energy materials such as foam. Generally, both the heat value and ash content are rather flexibly treated in these applications, and therefore open for negotiation (Interviewee 3 \& Interviewee 4). Hence, the fractions ZA, ZB, and ZC show a much higher potential for energy recovery than the others, given that a reduction of the ash content could be achieved. Moisture content is another important factor when feeding residues into the incinerators or cement kilns. However, it is not usually considered as a gate requirement. Cement kilns normally do not feed material with a moisture content above 5\% (wet basis) into the main burner but could instead use such fuel in the calciner, which is technically not affected by the moisture content (Interviewee 3 \& Interviewee 4). Municipal waste incinerators usually accept up to 40\% (wet basis) moisture. Generally, the moisture content in fines remains around 15\% (wet basis), with minute variation, irrespective of the size fraction, and the required conditions are not problematic.

In contrast to other fuel properties, the limit values on chlorine concentration are much stricter, especially due to the potentially corrosive effects that this substance has on the plant equipment and the emission stack. Cement kilns are prepared to slightly compromise on the chlorine limit, given a substantial benefit. For example, the cement kilns are willing to accept fuel with chlorine concentrations up to $1 \%$ instead of the original $0.8 \%$ (Figure 7), provided the energy content is as high as $25 \mathrm{MJ} / \mathrm{kg}$ (Interviewee 3). Reduction of the chlorine concentration by mixing shredder fines with zero/low-chlorine waste streams such as tyres is also an option (Interviewee 4). A general observation is that both the chlorine concentration and variation in occurrence reduces towards the smaller size fractions. Unfortunately, the most calorific fractions of shredder fines (i.e. ZA and ZB) also have the highest chlorine concentrations, meaning that pre-treatment would most likely be required to fulfil the gate requirements. The chlorine concentration in fraction $\mathrm{ZC}$ lies around the margin for both applications, which leaves some room for negotiation.
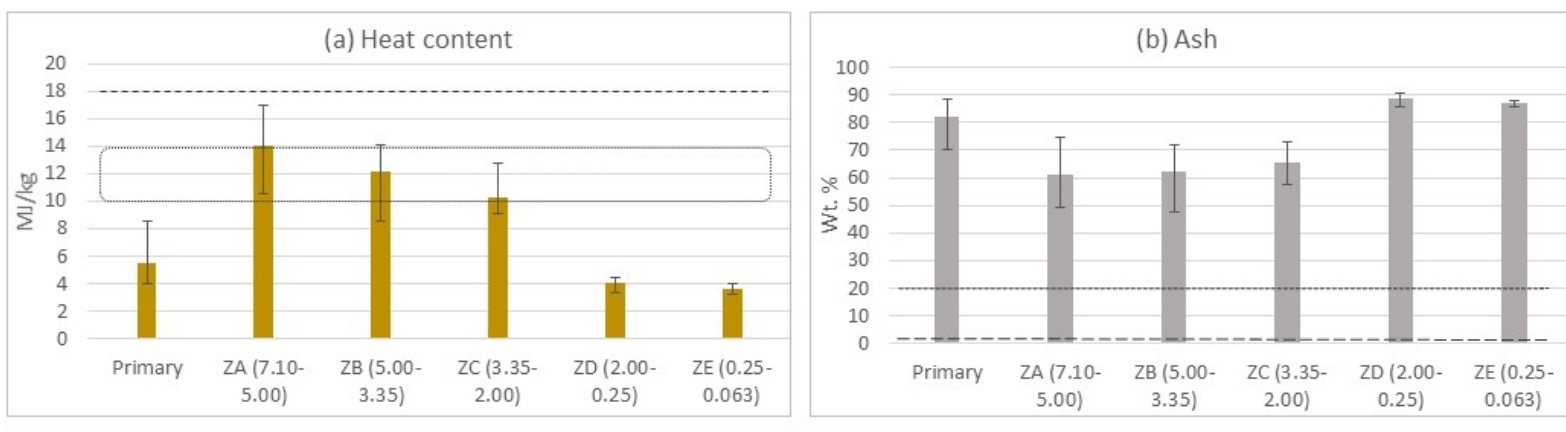

(c) Moisture (w.b.)
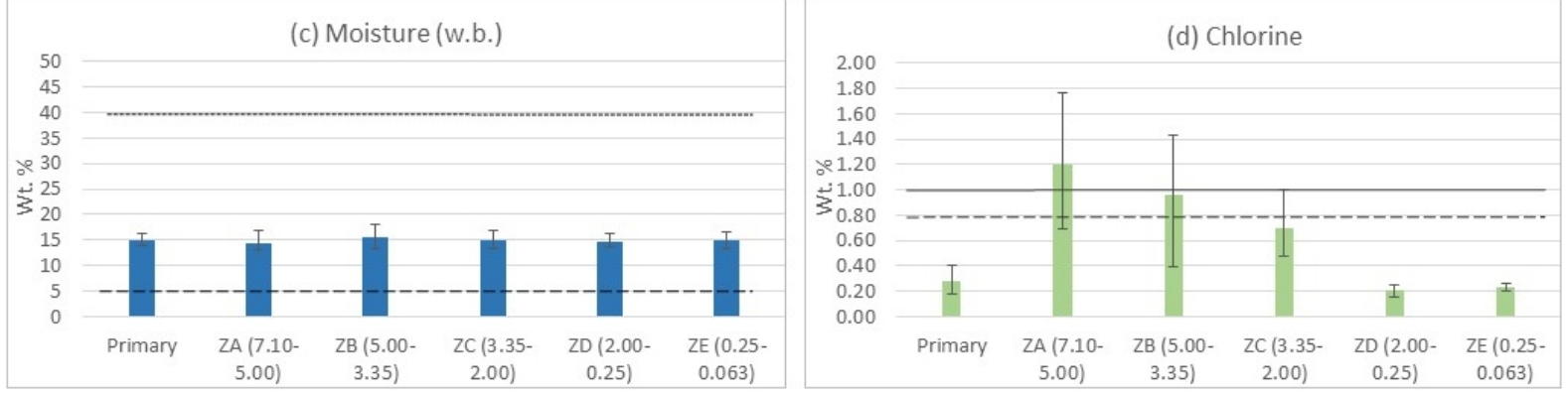

Figure 7: Weekly averages of fuel properties in the six fractions and respective gate requirements in order to be used in cement kilns and municipal waste incinerators for energy recovery. The variation of content/concentration over the entire nine-week period is also shown. The dashed lines and dotted lines represent the gate requirements for cement kilns and municipal waste incinerators, respectively. 
The concentrations of metals play a significant role concerning the feasibility of accepting fines as a fuel by the different users as well. In the case of cement kilns, regulatory conditions exist regarding the maximum allowable metals content in the feed material (Table 2). These limit values are expressed as total values for different groups of metals. In the case of municipal waste incineration, the values are specified for individual 131 metals by the different users.

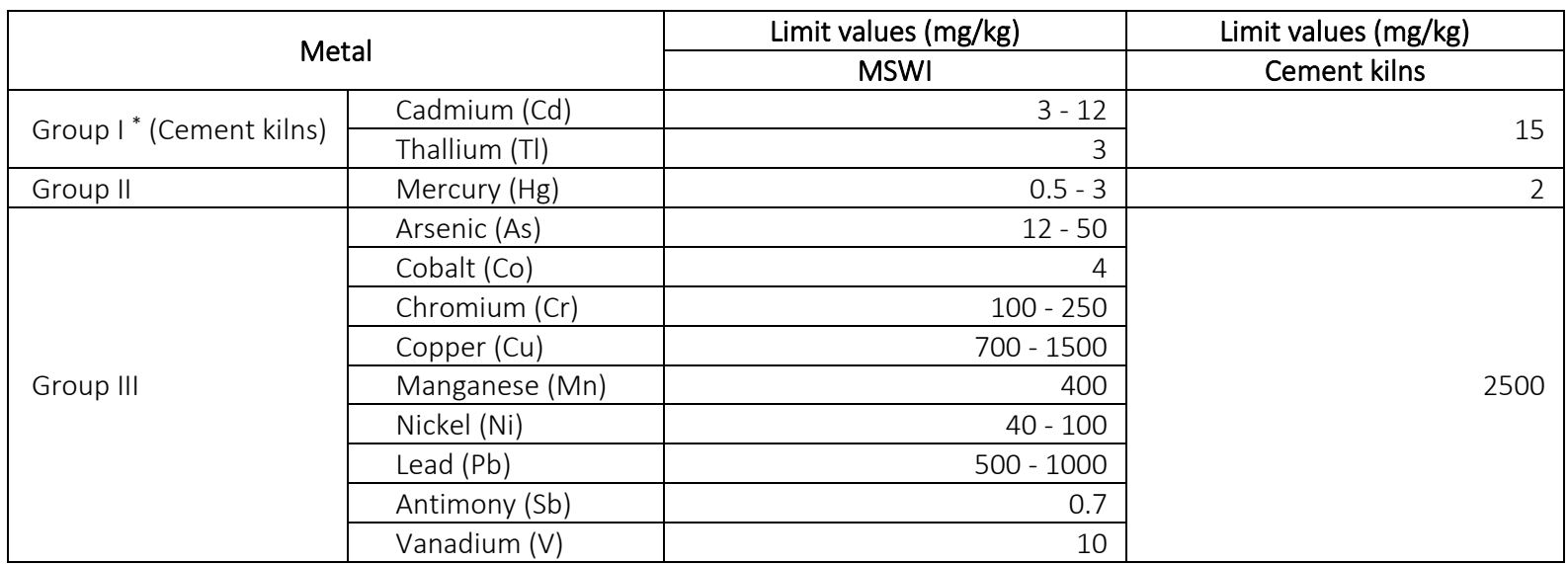

Table 2: Requirements on maximum metals concentrations in feed material to cement kilns and municipal solid waste incinerators (Interviewee 3, Interviewee 4, and Interviewee 5). The values for cement kilns are regulatory limits whereas the values for MSWI are the range constructed by the gate requirements of users according to the interviewees.

* Group I consists of both thallium (TI) and cadmium. However, the thallium concentration was not analysed in the analysis.

In general, the average concentrations of the above metals in shredder fines significantly exceed these limit values (Figure 8). The only exceptions are the average concentration of cadmium (excluding variation) and the average concentration of mercury (excluding variation) in the $\mathrm{ZA}$ and $\mathrm{ZB}$ fractions. For mercury, the high positive variations are caused by the unusually high concentrations in the week nine sample (discussed in Section 3.2). The limit values are strictly regarded in the use of fines as fuel, and therefore demands pretreatment for metals removal. There, high levels of variation in the most critical metals (Group I and Group II) will be a great challenge. Copper concentration also requires special attention, as it exceeds the limit value by several orders of magnitude.
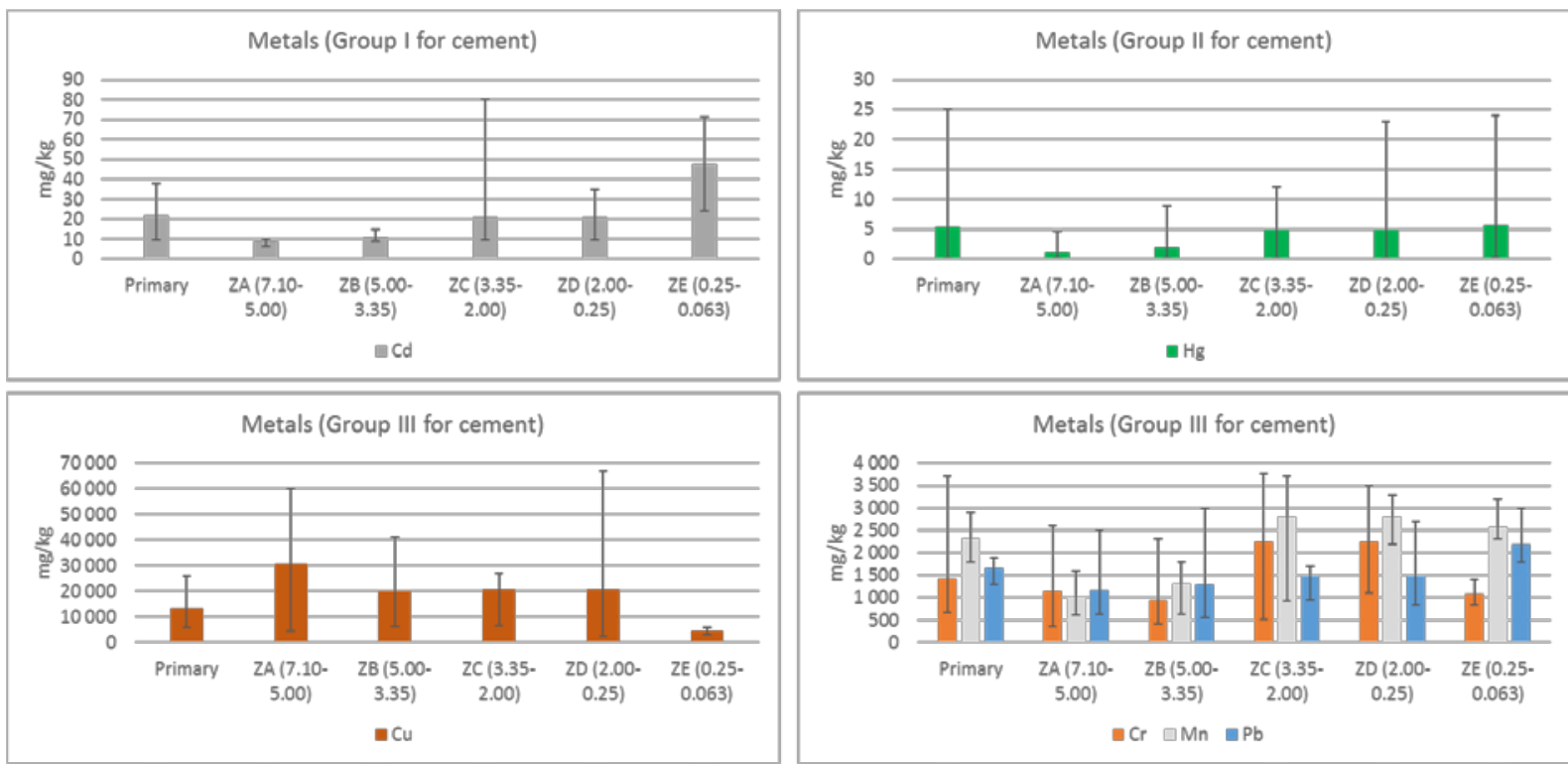

Figure 8: Weekly averages of metals concentration in the six fractions of shredder fines are presented. Only the most abundant metals are shown. The variation of the concentration over the nine-week period in terms of maximum and minimum values is also shown. Copper is shown separately because of the very high concentrations compared to the other metals. The metals are divided into the same groups as classified in Table 2. Of the other metals in Group III, only the three most concentrated metals are shown. 


\subsection{Recovery as bulk-material in construction applications}

In Sweden, the incentives for using secondary materials in construction applications is generally increasing and will continue to do so in the years to come (Interviewee 6, Interviewee 7, and Interviewee 8). The main reasons for this are the continuous pursuit of improved environmental performance by the companies and the potential to reduce transportation costs via opting for using raw materials in close proximity to the construction site (Interviewee 6).

At present, crushed concrete from demolition projects and obsolete asphalt are the most commonly used secondary materials in construction-related applications, replacing natural aggregates such as crushed rock and gravel. Shredder fines is seemingly less preferred over these materials, owing to its comparatively low availability and high heterogeneity. The heterogeneity itself is not a problem as long as the material meets the user and regulatory requirements (Interviewee 7, and Interviewee 8); rather, it is perceived by the construction companies to be less likely to meet the regulatory requirements concerning pollutants (especially metals). Ultimately, it will be the suppliers of fines that will have to ensure that fines meets these requirements. This is because the construction companies are not driven to do it by themselves, as the obtaining of such a clearance is often a time-consuming and resource-intensive process. Additionally, the procedures for using the other alternatives (demolition concrete and asphalt) are already established (Interviewee 6, Interviewee 7, and Interviewee 8).

Due to the potential environmental and human health risk, the heavy metals are regarded with great caution in the use of secondary materials in construction applications in Sweden. There is no well-defined process in the country that regulates such applications, and the cases are handled individually by the respective municipality. The Swedish EPA (Naturvårdsverket) has developed guidelines regarding maximum limits of contaminants for the different types of applications (Table 3). These guiding values primarily address the concentration of metals. There, the total concentration of the metals is prioritised while the leaching concentration of metals are considered secondarily. The total concentration of certain polycyclic aromatic hydrocarbons (PAHs) are also considered secondarily. The "less than low" risk level carries the fundamental guiding values for any ground construction application that takes place in public places such as parks, playgrounds, roads, parking lots, etc. The use of secondaries as cover material in landfills is subjected to a different set of guidelines. The intention of these values is not to use as obligatory, but rather, to assist the municipalities in performing site-specific assessments and decision making based on local conditions (Swedish EPA, 2010).

The total and leaching metal concentrations were used for the benchmarking in this study. The average total concentrations of all the metals in all the fractions of shredder fines exceed the guiding values provided by the Swedish EPA for the two types of construction applications, and the concentrations increase towards the smaller size fractions (Figure 9). Particularly, the average concentrations of the three most critical metals recognised by the Swedish EPA (i.e. cadmium, mercury, and lead) exceed the limit values and also show high positive variations, i.e. high maximum concentrations. It is also noteworthy that the average concentrations of the three metals increase towards the smaller size fractions. Copper and zinc are the two most abundant regulated metals in shredder fines, and even though not as hazardous, the total concentrations of these metals (including the positive variation) are around three orders of magnitude higher than the regulatory guiding values. Concentrations of several other metals such as chromium $(\mathrm{Cr})$, nickel $(\mathrm{Ni})$ and arsenic (As) display a similar pattern. In contrast, the leaching concentrations of metals in the analysed samples, are under the limit values in many of the fractions (Figure 9). Furthermore, the leaching concentration generally does not display as much of a characteristic variation across the different size fractions. The leaching concentrations of arsenic, cadmium, chromium, and mercury were under the minimum detectable levels of the laboratory analysis, i.e. As $0.20 \mathrm{mg} / \mathrm{kg}, \mathrm{Cd} 0.03 \mathrm{mg} / \mathrm{kg}, \mathrm{Cr} 0.20 \mathrm{mg} / \mathrm{kg}$, and $\mathrm{Hg} 0.01 \mathrm{mg} / \mathrm{kg}$. Thus, these metals are not shown on the figure. The leaching concentration of lead (one of the three most critical metals) increases towards the smaller size fractions, except for in the smallest size fraction, where a low occurrence can be observed. The leaching concentrations of the other two most 
critical metals, cadmium and mercury, remain unchanged between the different size fractions. Of the other metals, the leaching concentrations of copper, zinc, and nickel do not display a particular pattern.

The real environmental and human health risk of metals, however, is related to their mobility rather than the concentrations. That is, to what extent these contaminants are biologically available (Singh and Lee, 2015a, 2015b). This is a consequence of many other factors such as the chemical form of constituents, their physical properties, material's $\mathrm{pH}$, characteristics of the application site, etc. Therefore, the current strong emphasis put on the total concentration of metals as the primary risk indicator by the Swedish EPA is therefore highly questionable. In this respect, the leaching concentration is a stronger indicator of the risk. Thus, recovery as bulk-material in construction applications would show more feasibility in municipalities that undertake a risk-based approach in environmental assessments, and less feasibility in municipalities that undertake a total-concentration-based approach. The fact that total concentrations have excessively surpassed the current regulatory guiding values, prudently suggests the need for pre-treatment measures in the latter case.

\begin{tabular}{|l|r|r|r|r|}
\hline \multirow{2}{*}{ Metals } & \multicolumn{2}{|c|}{ Total concentration $(\mathrm{mg} / \mathrm{kg})$} & \multicolumn{2}{c|}{ Leaching concentration L/S 10 (mg/kg) } \\
\cline { 2 - 5 } & Ground construction & Landfill covering & Ground construction & \multicolumn{1}{c|}{ Landfill covering } \\
\hline Arsenic $(\mathrm{As})$ & 10 & 10 & 0.09 & 0.4 \\
\hline Lead $(\mathrm{Pb})$ & 20 & 200 & 0.2 & 0.3 \\
\hline Cadmium (Cd) & 0.2 & 1.5 & 0.02 & 0.007 \\
\hline Copper (Cu) & 40 & 80 & 1 & 0.6 \\
\hline Chromium (Cr) & 40 & 80 & 0.01 & 0.3 \\
\hline Mercury (Hg) & 0.1 & 1.8 & 0.4 & 0.01 \\
\hline Nickel (Ni) & 35 & 70 & 4 & 0.6 \\
\hline Zinc (Zn) & 120 & 250 & 3 \\
\hline
\end{tabular}


Total concentrations

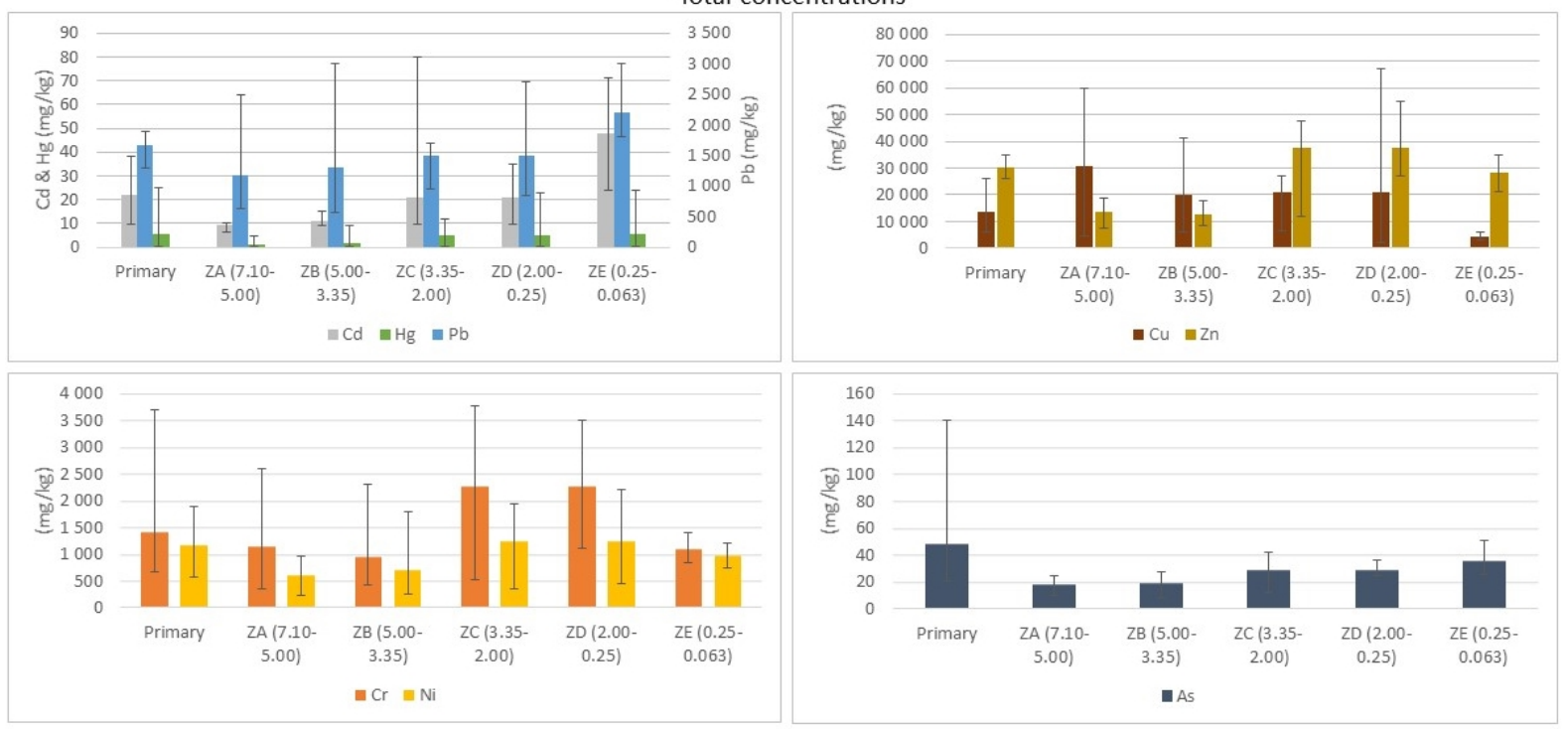

Leaching concentrations
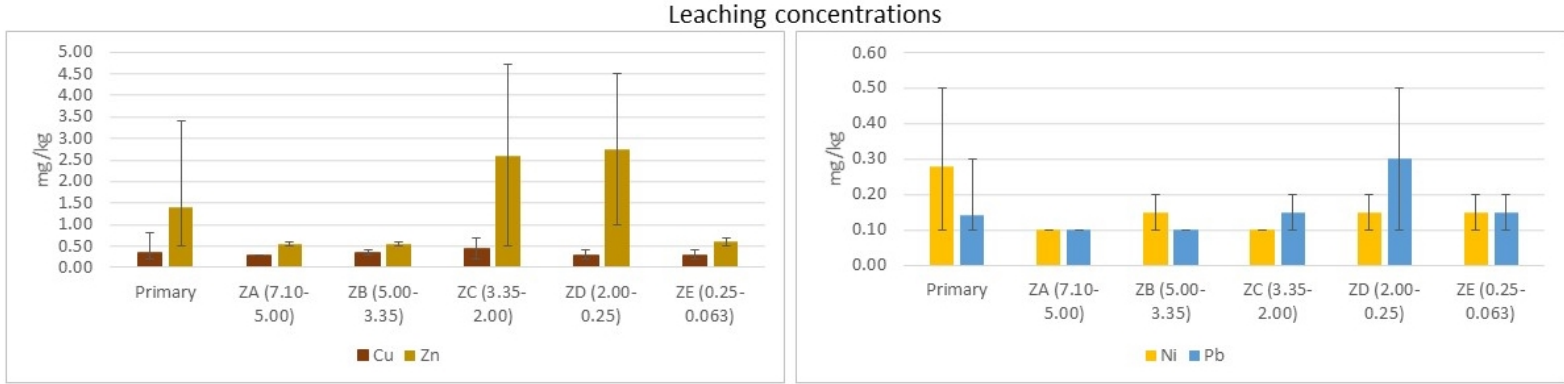

Figure 9: Distribution of total concentration and leaching concentration (L/S 10) of metals in the primary and sieved fractions of shredder fines. The variation in concentrations over the entire nine-week period is also shown in terms of maximum and minimum values. The limit values given by the Swedish EPA guidelines are provided separately in Table 3. Leaching concentration of certain metals could not be shown because their concentrations were below the detectable limits of the tests. 


\section{shredder fines}

221 The results of this study have several implications for future research, both when it comes to the selection different applications) and recovery strategies for shredder fines. The conducted benchmarking clearly shows that shredder fines, neither as a whole nor in different size fractions, currently fulfils all the gate and regulatory requirements of the studied recovery applications (Table 4) owing to various material constraints. Nevertheless, sieving fines deem a plausible prerequisite since it could improve the marketability of certain size fractions over the others with respect to different applications, and the efficiency of both upgrading and recovery processes, in general, would benefit from a more homogenous material in terms of particle size.

Concerning the upgrading of shredder fines, the main challenge is that several material constraints need to be addressed simultaneously in order to facilitate recovery. In that regard, various processes that potentially could address such constraints have been reported in the literature. For instance, several physicomechanical separation processes could potentially be used to enrich the copper content and thereby meet the gate requirements of smelters. Shaker tables, jigs, and hydro-cyclones are all examples of such processes for the separation different materials such as metals, minerals, and organics (Allen and Fisher, 2007; Gent et al., 2015). Processes targeting the separation of specific metals, such as electrostatic separation and eddy current separation are other possible options (Furuyama and Bissombolo, 2005; Izumikawa, 1999). However, the employment of such processes would not solve the issues related to the high concentrations of undesirable metals such as mercury, cadmium and aluminium in the ZA-ZD fractions. Similarly, the separation of minerals and metals from the organics could potentially be an effective way to reduce the ash content in the ZA-ZC fractions, thereby also increasing the heating value. Although such approaches could produce a more desirable fuel for cement kilns and waste incinerators, the need to reduce both the chlorine and heavy metal concentrations would not be addressed. When it comes to addressing the specific challenge of heavy metal contamination of shredder fines, several different processes have been developed in research. Physicomechanical separation (Kurose et al., 2006), mechanochemical and physical immobilisation (Mallampati et al., 2016; Pera and Ambroise, 2005), and the use of solvent (aqueous acidic solutions) extraction methods (Singh et al., 2016b; Singh and Lee, 2015c, 2015b) are examples of such processes. However, the latter extraction alternative is not yet conventional due to technical and economic challenges.

In relation to the different valorisation applications, the share of shredder fines that could be utilised varies significantly between the different applications (Table 4). The realisation of the strategy to recover valuable materials such as copper and energy carriers is limited to a few of the size fractions, whereas the strategy to minimise the disposable quantity could only be effectively achieved by enabling the use of shredder fines as bulk-material in construction applications. Sending fines for copper recovery in smelting would only recover less than $2 \%$ of the fines (given all the fractions ZA-ZD are utilised). That also means everything else other than the recovered copper and combusted organic content (i.e. more than $86 \%$ of the fines) would have to be disposed of. It is worth noticing that the utilisation of only ZA-ZB fractions in copper smelting would only recover a 19\% share of the total copper available in fines. However, if ZC-ZD fractions were also utilised (despite the need to address higher contamination levels) the theoretically recoverable share could rise up to $96.5 \%$ of the total copper content. Energy recovery in cement kilns and municipal waste incinerators would recover about $6 \%$ of the fines as energy carriers (organic content) given that the fractions ZA-ZC are utilised. That way, $53 \%$ of the total energy content in fines is recoverable in each of these applications, nevertheless, 94\% fines (i.e. ash from ZA-ZC and the remaining fractions ZD-ZE) would have to be disposed of. However, if separated, the minerals content in fractions ZA-ZC, which is about $10 \%$ of the total fines, could be recovered as feed material for clinker in cement kilns. In contrast to the above applications, the recovery as bulk-material in construction applications would recover $100 \%$ of the material. However, there, the opportunities to recover specific resources is lost. These findings imply that the integration of the different processes is therefore key in upgrading the material properties and realising the full resource potential in fines. 


\begin{tabular}{|c|c|c|c|c|c|c|c|}
\hline \multirow[t]{2}{*}{ Type of valorisation } & \multirow{2}{*}{$\begin{array}{c}\text { Potentially } \\
\text { applicable fractions }\end{array}$} & \multirow{2}{*}{$\begin{array}{l}\text { Main challenges for } \\
\text { material upgrading }\end{array}$} & \multicolumn{2}{|c|}{$\begin{array}{l}\text { Type and extent of unfulfilled } \\
\text { requirements for valorisation }\end{array}$} & \multirow{2}{*}{$\begin{array}{l}\text { Significance of } \\
\text { requirement }\end{array}$} & \multirow[t]{2}{*}{ Total recoverable share of fines } & \multirow{2}{*}{$\begin{array}{c}\text { Remaining share of fines } \\
\text { in need of disposal }\end{array}$} \\
\hline & & & Gate & Regulatory & & & \\
\hline \multirow{6}{*}{$\begin{array}{l}\text { Copper recovery in } \\
\text { smelting }\end{array}$} & \multirow{3}{*}{$\begin{array}{l}\text { ZA }(7.10-5.00 \mathrm{~mm}) \\
\text { ZB }(5.00-3.35 \mathrm{~mm})\end{array}$} & Low Cu conc. & Well below & - & Negotiable & \multirow{3}{*}{$<0.5 \%$ (as copper) } & \multirow{3}{*}{$73 \%$} \\
\hline & & Occasionally high Hg conc. & Well above & - & Strict & & \\
\hline & & High Al conc. & Well above & - & Negotiable & & \\
\hline & \multirow{3}{*}{$\begin{array}{l}\mathrm{ZC}(3.35-2.00 \mathrm{~mm}) \\
\mathrm{ZD}(2.00-0.25 \mathrm{~mm})\end{array}$} & Low Cu conc. & Well below & - & Negotiable & \multirow{3}{*}{$<1.5 \%$ (as copper) } & \multirow{3}{*}{$88 \%$} \\
\hline & & Occasionally high Hg conc. & Well above & - & Strict & & \\
\hline & & High Al conc. & Well above & - & Negotiable & & \\
\hline \multirow{4}{*}{$\begin{array}{l}\text { Energy recovery in } \\
\text { cement kilns }\end{array}$} & \multirow{4}{*}{$\begin{array}{l}\text { ZA }(7.10-5.00 \mathrm{~mm}) \\
\text { ZB }(5.00-3.35 \mathrm{~mm}) \\
\text { ZC }(3.35-2.00 \mathrm{~mm})\end{array}$} & Low heat value & Slightly below & - & Negotiable & \multirow{4}{*}{$\begin{array}{l}6 \% \text { (as energy carriers) } \\
10 \% \text { (as feed material in clinker) }\end{array}$} & \multirow{4}{*}{$84 \%$} \\
\hline & & High ash content & Well above & - & Negotiable & & \\
\hline & & High $\mathrm{Cl}$ conc. & Slightly above & - & Strict & & \\
\hline & & High metal conc. & - & Well above & Strict & & \\
\hline \multirow{3}{*}{$\begin{array}{l}\text { Energy recovery in } \\
\text { MSWI }\end{array}$} & \multirow{3}{*}{$\begin{array}{l}\text { ZA }(7.10-5.00 \mathrm{~mm}) \\
\text { ZB }(5.00-3.35 \mathrm{~mm}) \\
\text { ZC }(3.35-2.00 \mathrm{~mm})\end{array}$} & High ash content & Well above & - & Negotiable & \multirow{3}{*}{$6 \%$ (as energy carriers) } & \multirow{3}{*}{$94 \%$} \\
\hline & & High Cl conc. & Slightly above & - & Strict & & \\
\hline & & High metal conc. & - & Well above & Strict & & \\
\hline $\begin{array}{l}\text { Bulk-material recovery } \\
\text { in ground construction }\end{array}$ & Whole of fines & High metal conc. & - & Well above & Strict & $100 \%$ (as filler material) & - \\
\hline $\begin{array}{l}\text { Bulk-material recovery } \\
\text { in landfill covering }\end{array}$ & Whole of fines & High metal conc. & - & Well above & Strict & $100 \%$ (as filler material) & - \\
\hline
\end{tabular}

valorisation, the potential for recovering specific materials and energy carriers as well as minimising the disposable quantity is also indicated. 


\section{Conclusions}

This study demonstrates the usefulness of employing a systematic approach to inform the initial development of integrated process schemes that are capable of exploiting the various resource potentials and addressing the various material constraints of shredder fines. Such systematic process development could only emanate from a comprehensive understanding of the physical and chemical properties of the material in question - knowledge which is often absent in current research on shredder fines. We, therefore, argue that any development of valorisation processes for shredder fines should start with a systematic sampling and material characterization, specifying average values as well as over time variations of an array of physical and chemical properties capable of indicating the resource potential as well as the extent of contamination. In addition, we conclude that knowledge about existing gate and regulatory requirements for secondary resources provide valuable input to the initial process design by indicating which material constraints need to be addressed by upgrading measures in order to enable different recovery routes, and thus, to realise the full resource potential of shredder fines. In essence, this study calls for a new approach to the valorisation of shredder fines that goes beyond isolated process development with narrow recovery objectives, and also is sensitive to the importance of both upstream (i.e. variation in material characteristics of shredder fines) and downstream conditions (i.e. market and regulatory requirements of the users of finesderived resources).

In general, there is a considerable potential for the utilisation of shredder fines in the five commercial applications investigated. Nevertheless, various challenges need to be overcome in order to achieve the full valorisation of the material. Valuable resources such as copper and energy carriers, and undesirables such as heavy metals, are not distributed in a way that some size fractions become clearly more appealing than the others. Nevertheless, certain size fractions do show more potential than the others when benchmarked against the gate and regulatory requirements of the different applications. Therefore, dividing fines into different size fractions would be a plausible prerequisite for the process development for upgrading and subsequent recovery. Anyways, research must go beyond the so far common approach of "addressing one problem with one process at a time" and focus on the development of integrated upgrading processes capable of addressing several material constraints simultaneously. Only then could different recovery strategies such as copper smelting, energy recovery and bulk-material recovery in construction, be combined and both recovery of valuable materials and utilisation of the whole of fines be achieved.

It is worth noting that the analytical approach used in this study is mainly useful for the initial formulation of process schemes that potentially could address the various resource potentials and material constraints of shredder fines simultaneously. A key topic for future research is then to evaluate and gradually improve the technical feasibility of such integrated upgrading and resource recovery processes. Such technicallyoriented research must, however, also acknowledge that the implementation of the developed processes is a multifaceted and challenging endeavour that also requires justification from an economic and environmental point of view. That is because, in the end, the implementation of process schemes will rely on the balancing of financial costs and environmental impacts from upgrading and recovery, with the financial revenues from recovered resources, avoided landfilling/disposal costs, and environmental savings of replaced primary production. We, therefore, stress the need to include such considerations already in an early phase of process development - a practice that has been largely uncommon in previous research on the development of valorisation processes for shredder fines. Finally, facilitating the realisation of different valorisation routes for shredder fines could further benefit from research on upstream issues that address various pollution sources already before the materials enter the shredder plants.

\section{Acknowledgements}

Financial support from the Swedish Foundation for Strategic Environmental Research (Mistra) is gratefully acknowledged. Additionally, thanks to the personnel of Stena Recycling AB involved in this study for facilitating sampling and characterisation of the material and for commenting on the manuscript. 


\section{References}

Ahmed, N., Wenzel, H., Hansen, J.B., 2014. Characterization of Shredder Residues generated and deposited in Denmark. Waste Manag. 34, 1279-1288.

https://doi.org/10.1016/j.wasman.2014.03.017

Allegrini, E., Maresca, A., Emil, M., Sommer, M., Boldrin, A., Fruergaard, T., 2014. Quantification of the resource recovery potential of municipal solid waste incineration bottom ashes. Waste Manag. 34, 1627-1636. https://doi.org/10.1016/j.wasman.2014.05.003

Allen, L.E., Fisher, M.M., 2007. Metal Recovery from Shredder Residue Fines. J. Mater. Manuf. 156, 154 160.

Bareel, P.-F., Bastin, D., Bodson, C., Frenay, J., 2006. Sampling of Fine Shredder Residues (FSR) and characterisation oriented to physical separations, in: Kongoli, F., R.G, R. (Eds.), Sohn International Symposium Advanced Processing of Metals and Materials 2006. The Minerals Metals and Materials Society, San Diego, Caliofrnia, pp. 359-372.

Cain, R.L., Goodship, V., Love, J.C., Smith, G.F., Tucker, N., 2000. Recycling of Automotive Shredder Residue (ASR) by co-injection moulding. Polym. Recycl. 5, 63-70.

Chinyama, M.P.M., 2011. Alternative Fuels in Cement Manufacturing. INTECH 135-152.

Cossu, R., Fiore, S., Lai, T., Luciano, A., Mancini, G., Ruffino, B., Viotti, P., Zanetti, M.C., 2014. Review of Italian experience on automotive shredder residue characterization and management. Waste Manag. 34, 1752-1762. https://doi.org/10.1016/j.wasman.2013.11.014

Cossu, R., Lai, T., 2015. Automotive shredder residue (ASR) management: An overview. Waste Manag. 45, 143-151. https://doi.org/10.1016/j.wasman.2015.07.042

Dou, X., Ren, F., Nguyen, M.Q., Ahamed, A., Yin, K., Chan, W.P., Chang, V.W.C., 2017. Review of MSWI bottom ash utilization from perspectives of collective characterization, treatment and existing application. Renew. Sustain. Energy Rev. 79, 24-38. https://doi.org/10.1016/j.rser.2017.05.044

European Commission, 2008. Directive 2008/98/EC of the European Parliament and of the Council of 19 November 2008 on waste and repealing certain Directives, Official Journal of the Europian Union.

European Commission, 2004. Methodology for the Analysis of Solid Waste (SWA-Tool) User Version. Vienna.

European Commission, 2000. Directive 2000/53/EC of The European Parliament and of the Council of 18 September2000 on end-of life vehicles. Communities 6, 34-42. https://doi.org/10.1016/j.jclepro.2010.02.014

European Commission Eurostat, 2011. Guidance on the interpretation of the term backfilling.

Fiore, S., Ruffino, B., Zanetti, M.C., 2012. Automobile Shredder Residues in Italy: Characterization and valorization opportunities. Waste Manag. 32, 1548-1559. https://doi.org/10.1016/j.wasman.2012.03.026

Fischer, T., 2006. Getting a return from residue. Scrap 63, 57-62.

Furuyama, T., Bissombolo, A., 2005. Recovery of Copper from Light ASR Materials by Dry Towermilling and Electrostatic Separation, in: European Metallurgical Conference, EMC 2005. GDMBMedienverl, Dresden.

Gent, M.R., Menéndez, M., Muñiz, H., Torno, S., 2015. Recycling of a fine, heavy fluff automobile shredder residue by density and differential fragmentation. Waste Manag. 43, 421-433. https://doi.org/10.1016/j.wasman.2015.06.010 
GHK and Bio Intelligence Service, 2006. A study to examine the benefits of the End of Life Vehicles Directive and the costs and benefits of a revision of the 2015 targets for recycling, re-use and recovery under the ELV Directive. Birmingham.

Gonzalez-Fernandez, O., Hidalgo, M., Margui, E., Carvalho, M.L., Queralt, I., 2008. Heavy metals' content of automotive shredder residues (ASR): Evaluation of environmental risk. Environ. Pollut. 153, 476-482. https://doi.org/10.1016/j.envpol.2007.08.002

Izumikawa, C., 1999. Metal recovery from ash of automobile shredder residue - Especially focusing on particle shape, in: Gaballah, I., Hager, J., Solozabal, R. (Eds.), REWAS'99: Global Symposium on Recycling, Waste Treatment, and Clean Technology. The Minerals Metals and Materials Society.

Kaddatz, K.T., Rasul, M.G., Rahman, A., 2013. Alternative fuels for use in cement kilns: Process impact modelling. Procedia Eng. 56, 413-420. https://doi.org/10.1016/j.proeng.2013.03.141

Konetschnik, D.S., Schneeberger, G., 2009. Recovery of Copper and Precious Metals from Shredder Residues, in: Harre, J. (Ed.), Proceedings of European Metallurgical Conference, 2009. ClausthalZellerfeld, Innsbruck, Austria, pp. 661-672.

Kurose, K., Okuda, T., Nishijima, W., Okada, M., 2006. Heavy metals removal from automobile shredder residues (ASR). J. Hazard. Mater. 137, 1618-1623. https://doi.org/10.1016/j.jhazmat.2006.04.049

Lewis, G., Gaydardzhiev, S., Bastin, D., Bareel, P.F., 2011. Bio hydrometallurgical recovery of metals from Fine Shredder Residues. Miner. Eng. 24, 1166-1171. https://doi.org/10.1016/j.mineng.2011.03.025

Mallampati, S.R., Lee, B.H., Mitoma, Y., Simion, C., 2016. Dual mechanochemical immobilization of heavy metals and decomposition of halogenated compounds in automobile shredder residue using a nano-sized metallic calcium reagent. Environ. Sci. Pollut. Res. 23, 22783-22792. https://doi.org/10.1007/s11356-016-7458-7

Miljösamverkan Västerbotten, 2014. Using waste as construction material (in Swedish).

Morselli, L., Santini, A., Passarini, F., Vassura, I., 2010. Automotive shredder residue (ASR) characterization for a valuable management. Waste Manag. 30, 2228-2234. https://doi.org/10.1016/j.wasman.2010.05.017

Pera, J., Ambroise, J., 2005. Stabilization of automotive shredder residue by calcium sulfoaluminate cement, in: I, G., Mishra, R., Solosabal, M., Tanaka, M. (Eds.), REWAS '04: Global Symposium on Recycling, Waste Treatment and Clean Technology. Minerals, Metals \& Materials Society, Madrid, Spain, pp. 13-18.

Péra, J., Ambroise, J., Chabannet, M., 2004. Valorization of automotive shredder residue in building materials. Cem. Concr. Res. 34, 557-562. https://doi.org/10.1016/j.cemconres.2003.09.004

Reuter, M.., Pitéterse, M.., Dalmijn, W.., 1999. Is the Pyrometallurgical Recovery of the Inorganic Material an Option for Automobile Shredder Residue?

Robson, S., Goodhead, T.C., 2003. A process for incorporating automotive shredder residue into thermoplastic mouldings. J. Mater. Process. Technol. 139, 327-331. https://doi.org/10.1016/S0924-0136(03)00549-1

Rossetti, V.A., Di Palma, L., Medici, F., 2006. Production of aggregate from non-metallic automotive shredder residues. J. Hazard. Mater. 137, 1089-1095. https://doi.org/10.1016/j.jhazmat.2006.03.048

Santini, A., Passarini, F., Vassura, I., Serrano, D., Dufour, J., Morselli, L., 2012. Auto shredder residue recycling: Mechanical separation and pyrolysis. Waste Manag. 32, 852-858. https://doi.org/10.1016/j.wasman.2011.10.030

Simona, S.-F., Havlik, T., Miskufova, A., 2017. Recycling of automotive shredder residue by granulometric separation. MM Sci. J. 1810-1813. 
https://doi.org/10.17973/MMSJ.2017_06_2016153

Singh, J., Lee, B.K., 2016. Recovery of precious metals from low-grade automobile shredder residue: A novel approach for the recovery of nanozero-valent copper particles. Waste Manag. 48, 353-365. https://doi.org/10.1016/j.wasman.2015.10.019

Singh, J., Lee, B.K., 2015a. Pollution control and metal resource recovery for low grade automobile shredder residue: A mechanism, bioavailability and risk assessment. Waste Manag. 38, 271-283. https://doi.org/10.1016/j.wasman.2015.01.035

Singh, J., Lee, B.K., 2015b. Reduction of environmental availability and ecological risk of heavy metals in automobile shredder residues. Ecol. Eng. 81, 76-81. https://doi.org/10.1016/j.ecoleng.2015.04.036

Singh, J., Lee, B.K., 2015c. Hydrometallurgical recovery of heavy metals from low grade automobile shredder residue (ASR): An application of advanced Fenton process (AFP). J. Environ. Manage. 161, 1-10. https://doi.org/10.1016/j.jenvman.2015.06.034

Singh, J., Lingamdinne, L.P., Yang, J.K., Chang, Y.Y., Lee, B.K., Koduru, J.R., 2017. Effect of pH values on recovery of nano particles (NPs) from the fine fraction of automobile shredder residue (ASR): An application of NPs for phenol removal from the water. Process Saf. Environ. Prot. 105, 51-59. https://doi.org/10.1016/j.psep.2016.10.011

Singh, J., Yang, J.K., Chang, Y.Y., 2016a. Synthesis of nano zero-valent metals from the leaching liquor of automobile shredder residue: A mechanism and potential applications for phenol degradation in water. Process Saf. Environ. Prot. 102, 204-213. https://doi.org/10.1016/j.psep.2016.03.013

Singh, J., Yang, J.K., Chang, Y.Y., 2016b. Quantitative analysis and reduction of the eco-toxicity risk of heavy metals for the fine fraction of automobile shredder residue (ASR) using H2O2. Waste Manag. 48, 374-382. https://doi.org/10.1016/j.wasman.2015.09.030

Swedish EPA, 2010. Recycling of waste in construction sector (in Swedish).

Swedish EPA, 2009. Guiding values for contaminated soil (in Swedish).

Swedish Standards Institute, 2006. Swedish Standard (SS-EN 14899-20045)_Characterisation of waste Sampling of waste materials - Framework for the preparation and application of Sampling Plan.

Vermeulen, I., Van Caneghem, J., Block, C., Baeyens, J., Vandecasteele, C., 2011. Automotive shredder residue (ASR): Reviewing its production from end-of-life vehicles (ELVs) and its recycling, energy or chemicals' valorisation. J. Hazard. Mater. 190, 8-27.

https://doi.org/10.1016/j.jhazmat.2011.02.088

Zorpas, A.A., Inglezakis, V.J., 2012. Automotive industry challenges in meeting EU 2015 environmental standard. Technol. Soc. 34, 55-83. https://doi.org/10.1016/j.techsoc.2011.12.006 